\title{
VIBRATONAL ANALYSIS OF ROTOR DYNAMIC SYSTEM USING FEA
}

\author{
P. RAVINDER REDDY ${ }^{1} \&$ B. BHARATH KUMAR ${ }^{2}$ \\ ${ }^{1}$ Principal and Professor, Department of Mechanical Engineering, Chaitanya Bharathi Institute of Technology, \\ Hyderabad, Telangana, India
}

${ }^{2}$ PG Student, Department of Mechanical Engineering, Chaitanya Bharathi Institute of Technology, Hyderabad, Telangana, India

ABSTRACT
The aim of this work is to analyze the dynamic behaviour of the rotor-shaft system and address the critical issues
associated with them. Initially, a simple Jeffcott rotor is analyzed in detail to determine its natural frequencies, critical
speeds from the Campbell diagram, the forward and backward whirl modes. This is followed by the analysis of rotor shaft
system in SAMCEF in order to understand its dynamic behaviour which involves the detailed analysis of the Campbell
diagrams, critical speeds, effect of the gyroscopic moments etc. Campbell diagrams are obtained and critical speeds, effect
of the gyroscopic moments etc. are identified and discussed. In SAMCEF, in order to analyse the critical speeds and mode
shapes, the analysis of critical speeds and stability analysis carried out. Next to this, analysis unbalance responses were
analysed from the harmonic response analysis. After the harmonic response, transient analysis was carried out to analyse
the unbalance responses with respect to the time variations.
KEYWORDS: Dynamic Behaviour, Rotor, Cambell Diagram, Gyroscopic Moments \& Harmonic Response

Received: Mar 26, 2020; Accepted: Apr 16, 2020; Published: May 04, 2020; Paper Id.: IJMPERDJUN202031

\section{INTRODUCTION}

Many years ago, engines didn't operate with any high velocity and because of that engines had less stability problems. Today the turbines have to be more efficient, that means that they need to have higher rotational speed and because of that the turbines may get stability problems. Stability problems are the reason why rotor dynamics are important when developing gas turbines. Any stability problem in the rotor can easily lead to disaster and end up to be very expensive. The engineer wants to avoid oscillations in a system because oscillations can shorten the lifetime of the machine. Oscillations can also make the environment around the machine intolerable with heavy vibrations and high sound. Rotor unbalance and misalignment are major concerns in rotating machinery. Unbalance is the most cause of machine vibration. The problem of unbalance in a system occurs due to an uneven distribution of mass and when the centre of gravity of rotor does not coincide with the axis of rotation. Unbalanced rotor generates vibration may damage rotor system components. In order to extend the life of machine, vibration due to unbalance must be reduced to acceptable level.

Rankine [1] performed the first analysis of a spinning shaft. He predicted that beyond a certain spin speed $"$. The shaft is considerably bent and whirls around in this bent form Jeffcott [2] proposed a flexible rotor mode1 to analyse the response of high speed rotating shafts to mass imbalance. Jeffcott model is basically a particle or pointmass or lumped mass representation. In order to reflect the rigid-body character of flexible rotating equipment, Stodola and Green [3] used a rigid-body model to include the effects of rotary inertia and gyroscopic coupling. When a rigid disk is not located at the mid-span of a shaft, use of the Stodola-Green model is an appropriate 
approach. Biezeno and Grammel [4] suggested the earliest methods for finding the critical speeds in the flexible rotors. Also, the rotor dynamics analysis considering the hydrodynamic bearings was done by Lund [5]. For the first main mode shape of a rotor supported on bearings, Lund [5] found two corresponding critical speeds. Gunter [6] studied the stability issues in rotor dynamics and his work was combined with Lund's work on the stability problems considering the damped critical speeds within a rotor-bearing system and it initiated "a great deal of interest" in this area. The response of the rotors exhibited "whirls" in the forward and the backward directions, which is studied by Bhat et al. [7] using Vanderplaats method. The effect of the disk inertia in a rotating state on a shaft was first found by Rayleigh [14]. This phenomenon, namely, the "gyroscopic effect" was studied and its effect on increasing the forward whirl natural frequency and decreasing the backward whirl natural frequency was analyzed by Stodola [3]. Rao [8] investigated the backward synchronous whirl in a flexible rotor with hydrodynamic bearings. Sinou, Villa and Thouverez[10,16] studied the forward and backward critical speeds in a rotor with flexible bearing support and vibration analysis of complex flexible rotor system. Genta [9] published a fast modal analysis technique based on splitting the gyroscopic and damping matrices into two parts and comparing these parts with simplified conditions of rotors. In more recent days, finite element method using softwares such as SAMCEF, DYROBES, ANSYS made it easy to plot the Campbell diagram. Finite element modelling also helped the engineers to study a variety of features in Campbell diagram such as effect of fluid film bearing properties on the critical speeds of rotors.

Reducing the model of a rotating structure considering damping and gyroscopic effect with methods such as dynamic reduction does not give reasonable answers. There are significant errors in the results. Friswell, Penny and Garvey [11] published a study on this topic to prove these problems. Coupled lateral and torsional vibrations in unbalanced rotors validating with a numerical example is studied by Al-Bedoor[12]. Investigation of the gyroscopic effects by the energy methods was performed by Carnegie [13] for the first time. Nelson and McVaugh [15] studied on the natural whirl speeds and unbalance response of a typical overhung system and made a comparison of results with an independent lumped mass analysis. Lees et al. [17] overviewed the recent evaluation in the field of rotor dynamics which has a significant practical importance. The models assists the complex turbo-machinery monitoring which includes rotor balancing, rotor bow, rotor misalignment, rotor crack and bearing parameter estimations. A finite element dynamic modal for rotor bearing system, which accounts gyroscopic moments and anisotropic bearings are developed using a modal truncation method by Y.A. Khulief et.al [18]. Sinha J.K., et.al [19] proposes a method that can reliably estimate both the rotor unbalance and misalignment from a single machine run-down. An alternative balancing methodology for rotating machinery is presented by T.S. Morais et.al [20]. Chun-biao Gan et.al [21] extended the nonparametric modelling technique to the uncertain Jeffcott rotor with disc offset, and the random matrix model is established. The parametric instability of flexible rotorbearing system under time-periodic base angular motions is analyzed by Qinkai Han et.al [22].

\section{MATERIALS AND METHODOLOGY OF ROTOR DYNAMIC SYSTEM}

A typical rotor shaft of a SGT gas turbine carries the compressor and turbine discs. The rotor will be supported at various locations normally by antifriction bearings. The preliminary requirement in the design of a rotor is that the critical speeds of the system should be away from the operating speed. Usual practice is to keep the critical speeds above the operating speeds as crossing the critical speed is difficult and risky. Table1 shows the materials and their properties for the shaft, compressor and turbine. For preliminary analysis, the Lumped mass models of compressor and turbine discs are considered by maintaining mass, inertia and CG positions of actual components. 


\section{Compressor}

The major dimensions of the impeller are: Inlet dia at hub $=35 \mathrm{~mm}$, Inlet dia at tip $=135 \mathrm{~mm}$, Exit dia at hub $=35 \mathrm{~mm}$, Exit dia at tip $=35 \mathrm{~mm}$, Axial length $=80 \mathrm{~mm}$, The average inlet diameter $=(35+135) / 2=85 \mathrm{~mm}$, the average inlet diameter $=(165+185) / 2=175 \mathrm{~mm}$, Volume of an equivalent mass model $=\mathrm{V}=(\Pi / 3) * \mathrm{~h}^{*}\left(\mathrm{R}^{2}+\mathrm{r}^{2}+\mathrm{R} * \mathrm{r}\right)=$ $(\Pi / 3) * 80 *\left(87.5^{2}+42.5^{2}+87.5 * 42.5\right)=1104270 \mathrm{~mm}^{3}$, Modified density to maintain the mass of $2 \mathrm{~kg}, \rho_{\mathrm{c}}=\mathrm{Mass} / \mathrm{Volume}$ $=2000 / 1104270$, Density $\rho_{\mathrm{c}}=0.0018111 \mathrm{gms} / \mathrm{mm}^{3}$ or $1811.1 \mathrm{~kg} / \mathrm{m}^{3}$.

\section{Turbine}

The major dimension of the impeller are:The average tip diameter $=169.1 \mathrm{~mm}$, Width of the turbine $=45.1 \mathrm{~mm}$, Volume of the equivalent disc $=\mathrm{V}=(\Pi / 4) * \mathrm{~d}^{2} * \mathrm{I}=(3.142 / 4)^{*}(169.1)^{2} * 45.1=1012869.8 \mathrm{~mm}$, Modified density to maintain the mass of $1.632 \mathrm{~kg}, \rho_{\mathrm{c}}=$ Mass $/$ Volume $=1632 / 1012869.8$, Density $\rho_{\mathrm{c}}=0.001787 .3 \mathrm{gms} / \mathrm{mm}^{3}$ or $17873 \mathrm{~kg} / \mathrm{m}^{3}$. Figure 1 shows the model and design of compressor and turbine.

Table 1: Material Properties of Shaft, Compressor and Turbine

\begin{tabular}{|l|c|c|c|}
\hline \multicolumn{1}{|c|}{ Material Properties } & Shaft & Compressor & Turbine \\
\hline Material Used & $17-4$ PH Steel & Titanium Alloy & Nimonic 90 \\
\hline Density $\left(\mathrm{kg} / \mathrm{m}^{3}\right)$ & 7800 & 4500 & 8180 \\
\hline Elastic Modulus $(\mathrm{GPa})$ & 197 & 110 & 213 \\
\hline Poisson's Ratio & 0.3 & 0.3 & 0.3 \\
\hline
\end{tabular}

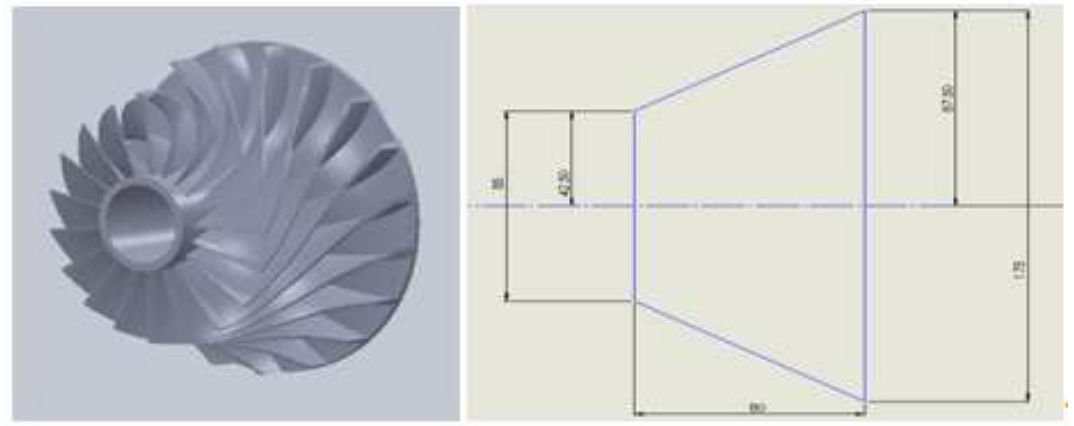

(a) Centrifugal Compressor Model and Design.

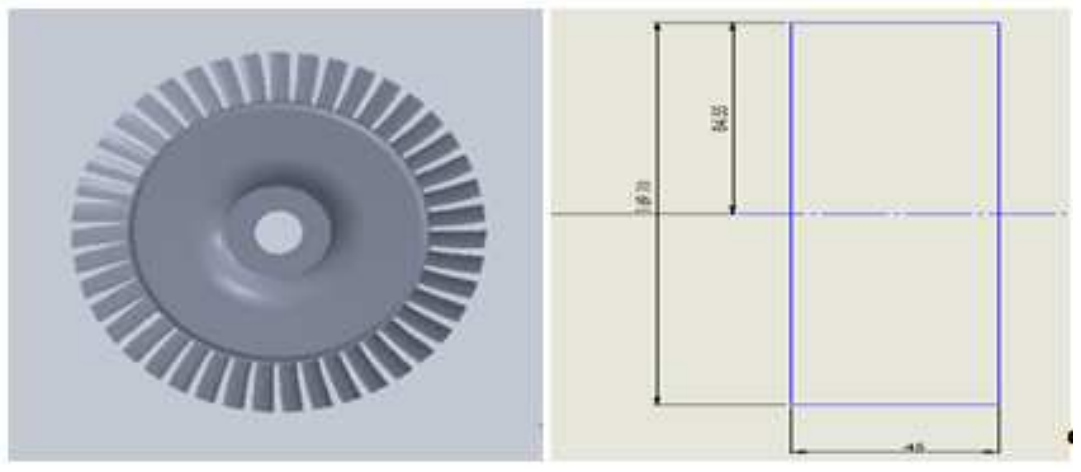

(b) Axial Turbine Model and Design.

Figure1: Centrifugal Compressor and Axial Turbine.

\section{Shaft}

The shaft on which the turbine and compressor are fixed have length $556.13 \mathrm{~mm}$ is made up of 17-ph structural steel material. The schematic of the shaft with major dimensions is shown in below figure 2 . 


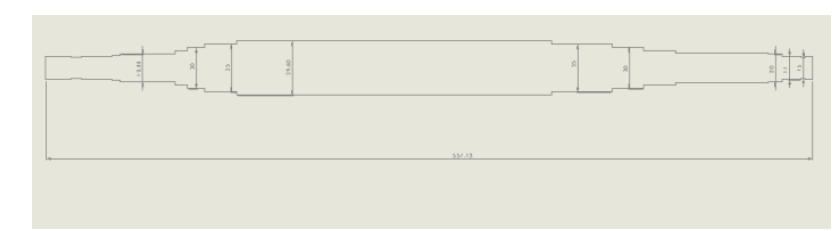

(a) Shaft 2D Model

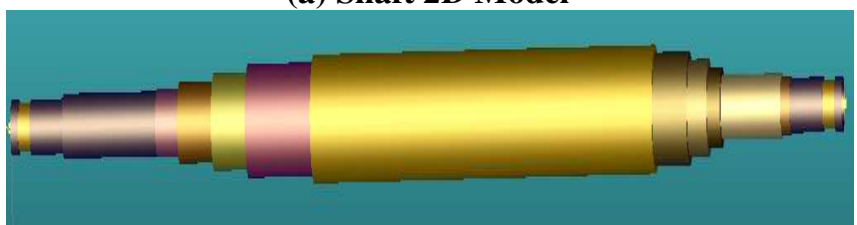

(b) Shaft 3D Model

Figure 2: The Geometric and 3D Model of a Shaft.

For this analysis, the property of the bearings i.e bearing stiffness $(\mathrm{K})$ is varied from $10 \mathrm{MN} / \mathrm{m}$ to $200 \mathrm{MN} / \mathrm{m}$ which was considered by the previous researchers. And the bearing span is also varied for the sensitivity analysis of the rotor dynamic system. The operating speed of the rotor dynamic system is considered as $43250 \mathrm{rpm}$. A scaled dimensions of the rotor shaft configuration is taken for the analysis. And for the dynamic analysis of the rotor system, SAMCEF software is used.

\section{RESULTS AND DISCUSSIONS}

The results of the rotor dynamic analyses of Jet engine rotor using SAMCEF are presented. The numerical simulation results related to different rotor configurations are shown with their sensitivity analysis. The comparison of results obtained from sensitivity analysis is discussed.

\subsection{Simulation Process of Solid Shaft Configuration 1: Bearing at Ends}

\subsubsection{Critical speed and Stability Analysis}

Input data for the analysis: Total length of solid stepped shaft $=557.1348 \mathrm{~mm}$, Mass of the compressor $=2 \mathrm{~kg}$, Center of mass point $=(0,0,57)$, Mass moment of Inertia $=(1.8 \mathrm{e}-3,1.8 \mathrm{e}-3,2.7 \mathrm{e}-3)$, Mass of the turbine $=1.632 \mathrm{~kg}$, Centre of mass point $=(0,0,40)$, Mass moment of Inertia $=(2.1 \mathrm{e}-3,2.1 \mathrm{e}-3,3.6 \mathrm{e}-3)$, Bearing stiffness $K_{1}=10 \mathrm{MN} / \mathrm{m}$ and $K_{2}=200 \mathrm{MN} / \mathrm{m}$, Bearing span $=487.3$, Rotor shaft is modelled in SAMCEF modeller, Behaviour, Material properties constraints are given in the Analysis data module. Mesh is generated in mesh module. For the simulation process, settings are defined in Solver module. Simulation settings: Initial frequency $=0 \mathrm{~Hz}$, Final frequency $=1000 \mathrm{~Hz}$, Number of steps $=200$, Number of eigen values $=12$. Figure 3 and Figure 4 are the line model and beam models of the solid circular stepped shaft consisting of lumped masses of the compressor and turbine with their center of mass positions and moment of inertia, and the compressor, turbine ends are simply supported with ground bearing as supporting elements. To analyse the mode shapes of the configuration sensitivity analysis is carried with changing the ground bearing stiffness from $10 \mathrm{MN} / \mathrm{m}$ to $200 \mathrm{MN} / \mathrm{m}$. The forward whirls are taken into the account because the unbalance force does not excite the backward-whirling modes, even though the synchronous line (1x line) intersects the backward frequency before the forward whirling mode. So synchronous forward whirl causes the unbalance excitation in the rotor dynamic system. Mass unbalances present in the rotor shaft system have more effective at the forward whirling modes rather than backward whirling modes. 


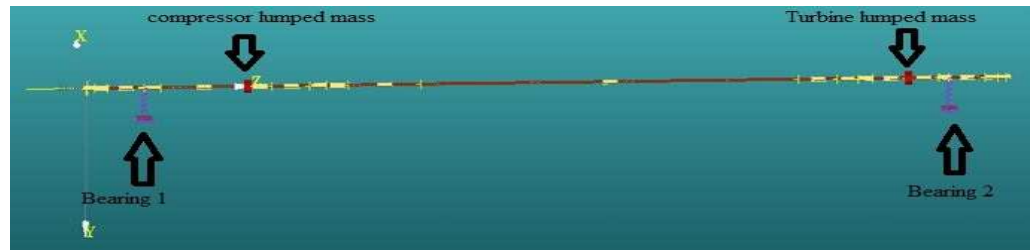

Figure 3: Line Model of Solid Circular Stepped Shaft.

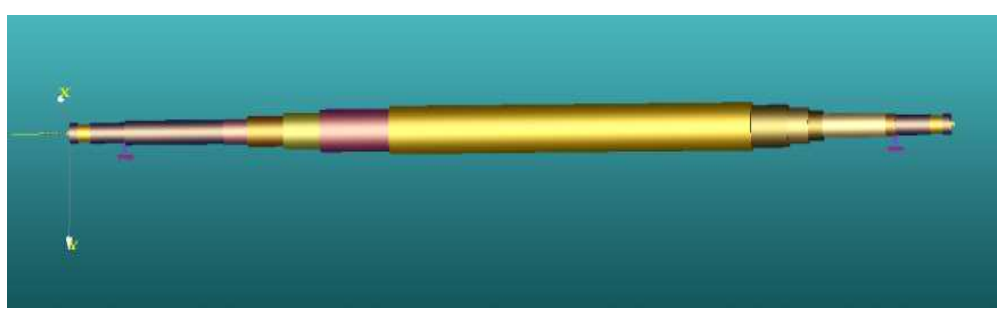

Figure 4: Beam model of Solid Circular Stepped Shaft.

\subsubsection{Sensitivity Analysis of the Solid Shaft Configuration 1}

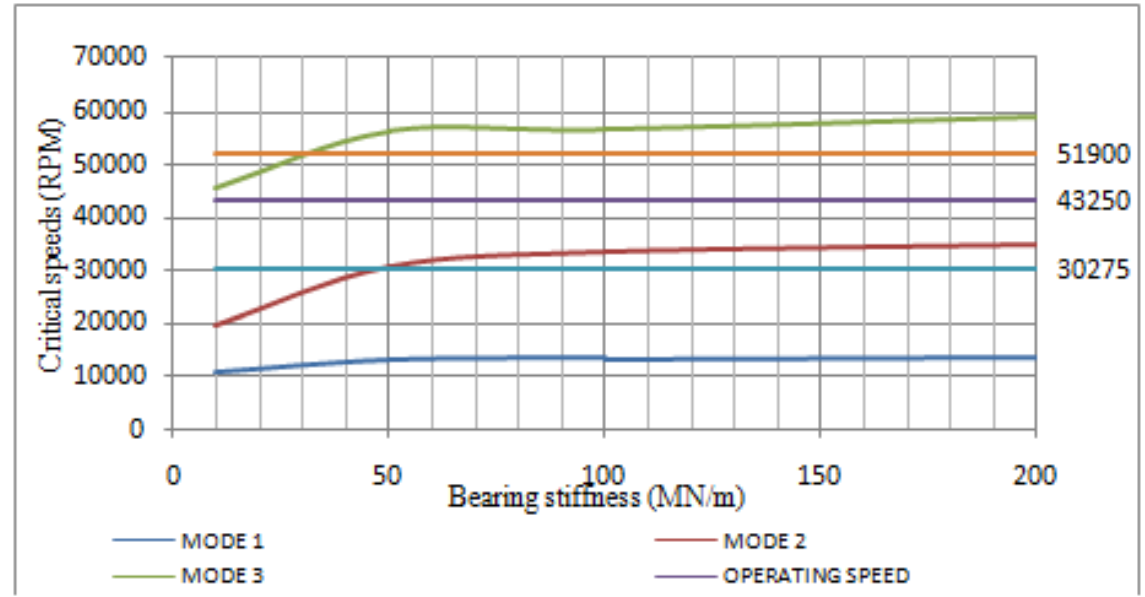

Figure 5: Sensitivity Analysis of the Solid Shaft Configuration 1.

From the Figure 5, it is observed that the Bending modes of the configuration would bring down to rigid body modes by reducing the bearing stiffness from $200 \mathrm{MN} / \mathrm{m}$ to $10 \mathrm{MN} / \mathrm{m}$. We can also observe that Mode 1 critical speeds are very far from the operating speed. And mode 2 is near to the $70 \%$ of operating speed line. And mode 3 line is just above the operating speed. So, we can conclude that the "safe operating zone" is below the Mode 2 critical speeds with bearing stiffness near to $50 \mathrm{MN} / \mathrm{m}$, And operating speed nearly 30,000 RPM. Here, we can also observe that mode shapes of the critical speeds have the deflection around $1 \mathrm{~mm}$ only.

\subsubsection{Campbell diagram and mode shapes}

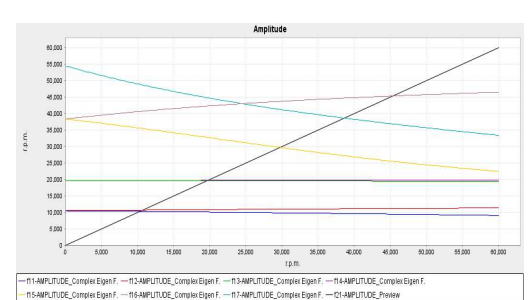

(a) Campbell Diagram.

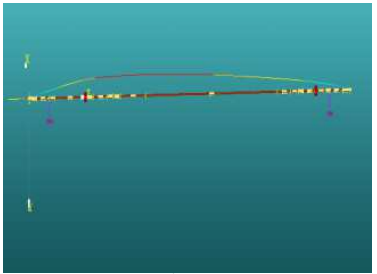

(b) $\mathbf{1}^{\text {st }}$ Mode. 


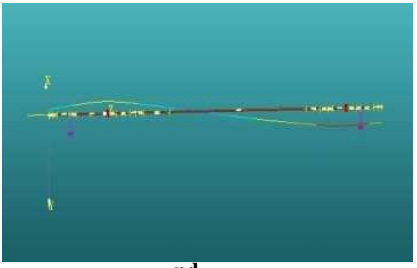

(c) $2^{\text {nd }}$ Mode.

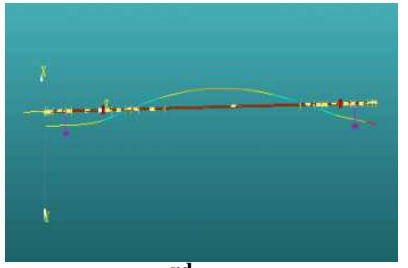

(d) $3^{\text {rd }}$ Mode.

Figure 6: Campbell Diagram with Bearing Stiffness $(K=10 \mathrm{MN} / \mathrm{m})$ and Mode Shape of Beam Corresponding to 1st Mode (Critical Speed: 10614 RPM), 2nd Mode (Critical Speed: 19627 RPM ), 3rd Mode (Critical Speed: 45269 RPM ).

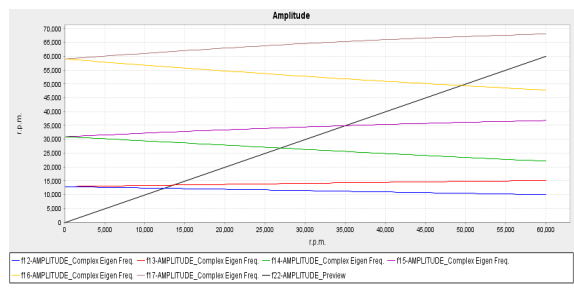

(a) Campbell Diagram

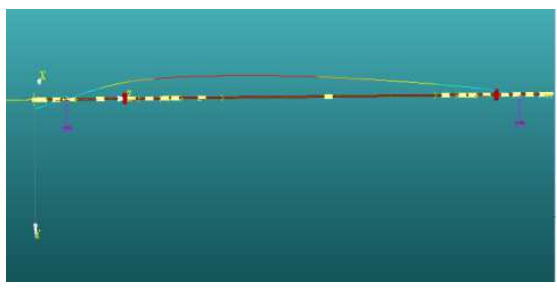

(b) $\mathbf{1}^{\text {st }}$ mode

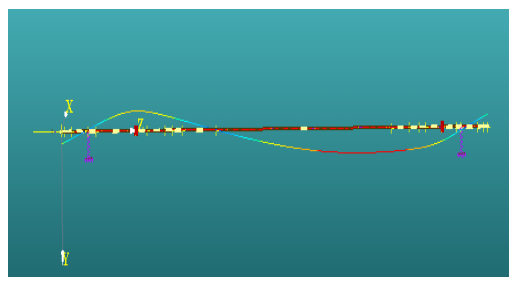

(c) $2^{\text {nd }}$ mode

Figure 7: Campbell Diagram with Bearing Stiffness $(K=220 \mathrm{MN} / \mathrm{m})$ and Mode Shape of Beam Corresponding to 1st Mode (Critical Speed: 13452 RPM), 2nd mode (Critical Speed : 34896RPM ).

Figure 6 and Figure 7 shows the Campbell diagram for the stiffness 10MN/m and 220MN/m and the critical speeds are varying if the bearing stiffness is $10 \mathrm{MN} / \mathrm{m}$ the first three critical speeds are 10614rpm, 19627rpm and 45269rpm whereas the bearing stiffness increased to $200 \mathrm{MN} / \mathrm{m}$ then the critical speeds are $13452 \mathrm{rpm}$ and 34896rpm respectively.

\subsection{Simulation Process of Hallow Shaft Configuration 1: Bearing at Ends}

For the hallow shaft analysis, shaft internal diameter considered is $12 \mathrm{~mm}$. The same analysis process carried out with Hallow shaft having same configurations, and sensitivity analysis of the critical speeds carried with two extreme bearing stiffness $200 \mathrm{MN} / \mathrm{m}$ and $10 \mathrm{MN} / \mathrm{m}$.

\subsubsection{Sensitivity Analysis of the Hallow Shaft Configuration 1}

From the Figure 8, it is observed that Mode 1 critical speeds are very far from the operating speed and mode 2 is near to the $70 \%$ of operating speed line and mode 3 line is above the operating speed. So, it indicates that the "safe operating zone" is below the Mode 2 critical speeds with bearing stiffness near to $45 \mathrm{MN} / \mathrm{m}$, and operating speed nearly 30,000 RPM. The mode shapes of the critical modes have the deflection around $1 \mathrm{~mm}$ only. 


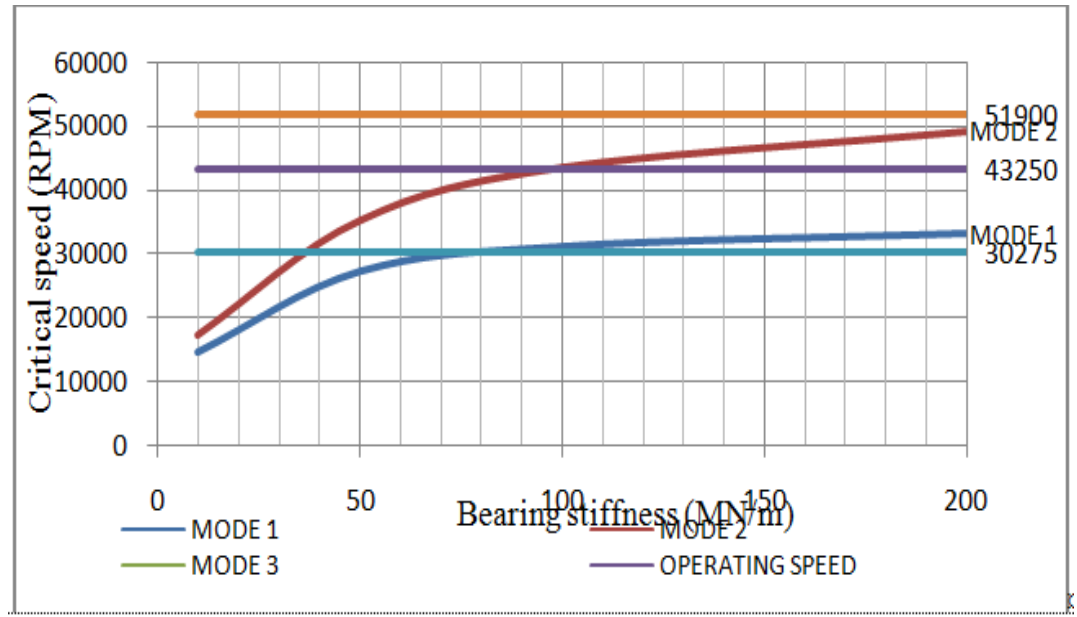

Figure 8: Sensitivity Analysis of the Hallow Shaft Configuration 1.

\subsubsection{Campbell Diagram and Mode Shapes}

For the above configuration, the Campbell diagram and mode shapes for the bearing stiffness of $10 \mathrm{MN} / \mathrm{m}$ and $200 \mathrm{MN} / \mathrm{m}$ are presented.

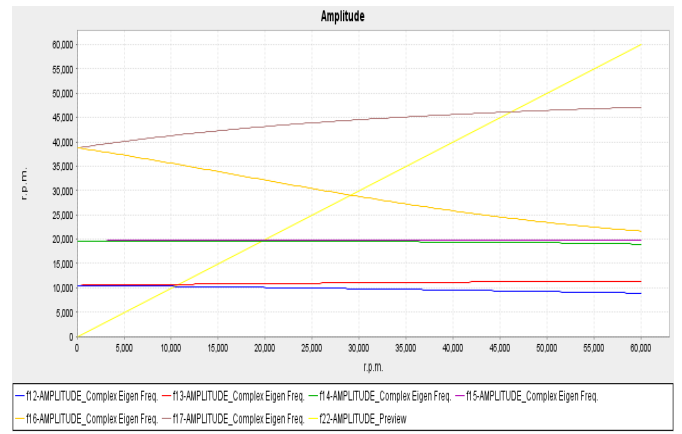

(a) Campbell Diagram

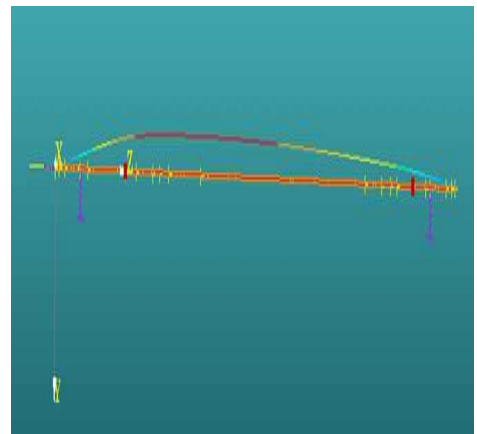

(b) $\mathbf{1}^{\text {st }}$ Mode

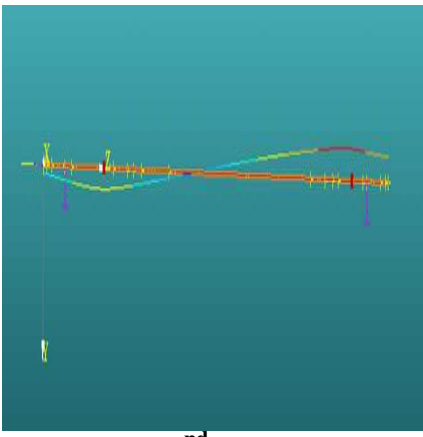

(c) $2^{\text {nd }}$ Mode

Figure 9: Campbell Diagram with Bearing Stiffness ( $\mathrm{K}=10 \mathrm{MN} / \mathrm{m})$ and Mode Shape of Beam Corresponding to 1st mode (Critical speed: 10724 RPM), 2nd mode (Critical speed : 19743RPM ).

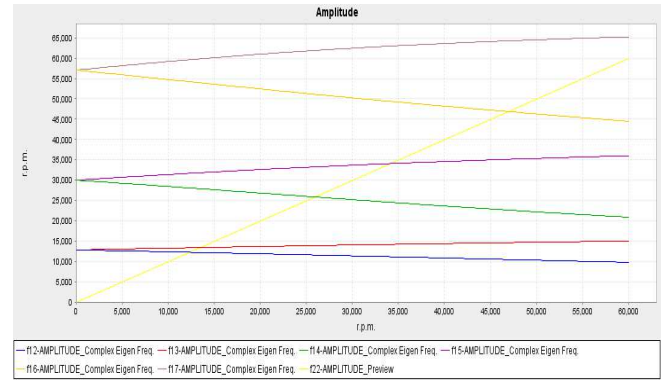

(a) Campbell Diagram

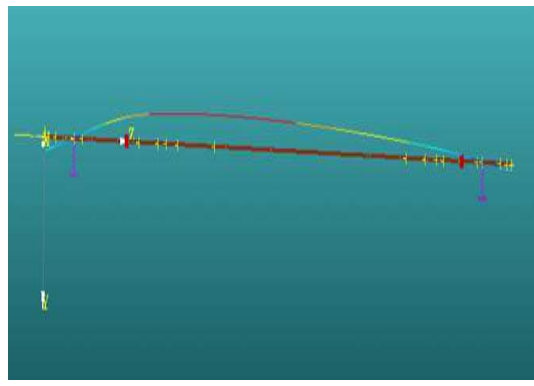

(b) $1^{\text {st }}$ Mode

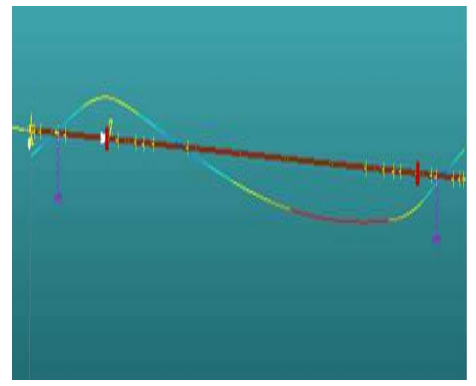

(c) $2^{\text {nd }}$ Mode

Figure 10: Campbell Diagram with Bearing Stiffness (K= 200MN/m) and Mode Shape of Beam Corresponding to 1st Mode (Critical Speed: 13411RPM), 2nd Mode (Critical Speed: 34064RPM ).

Figure 9 and Figure 10 shows the Campbell diagram for the stiffness 10MN/m and 200MN/m and the critical speeds are varying if the bearing stiffness is $10 \mathrm{MN} / \mathrm{m}$ the first two critical speeds are $10724 \mathrm{rpm}, 19743 \mathrm{rpm}$ whereas the bearing stiffness increased to $200 \mathrm{MN} / \mathrm{m}$, then the critical speeds are $13411 \mathrm{rpm}$ and $34064 \mathrm{rpm}$ respectively. From the 
sensitivity analysis of rotor dynamic configuration 1 with solid and hallow shaft, it is clear that solid configuration has more feasible safe operating speed range than the hallow configuration.

\subsection{Simulation Process of Solid Shaft Configuration 2: Overhang at Turbine}

\subsubsection{Critical Speed and Stability Analysis}

The same procedure is followed without any change except the bearing span which is taken as 432.5 mm. Figure 11 shows the line model and beam models of the solid circular stepped shaft consisting of lumped masses of the compressor and turbine with their center of mass positions. In this configuration, Compressor end is simply supported and overhang at Turbine end is considered with ground bearing as supporting elements. To analyse the mode shapes of the configuration sensitivity analysis has done with changing the ground bearing stiffness from $10 \mathrm{MN} / \mathrm{m}$ to $200 \mathrm{MN} / \mathrm{m}$.

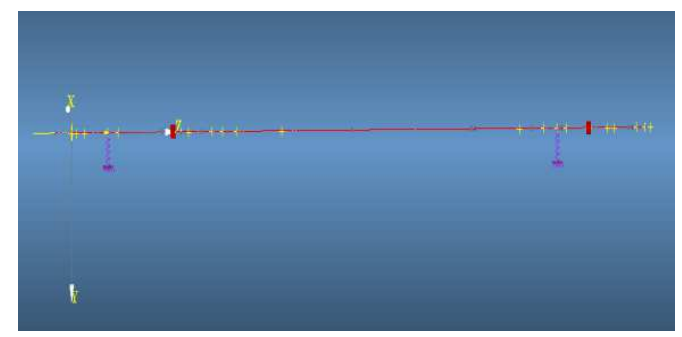

(a) Line Model

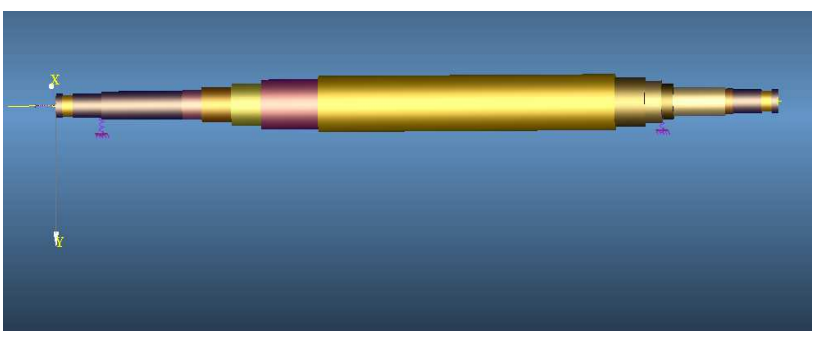

(b) Beam Model

Figure 11: Beam Model of Solid Circular Stepped Shaft.

\subsection{Simulation Process of Hallow Circular Stepped Shaft Rotor Dynamic Final}

\section{Configuration with Bearing Stiffness $\quad(K)=30 \mathrm{MN} / \mathrm{M}$}

The final computed values of final configuration with bearing stiffness $30 \mathrm{MN} / \mathrm{m}$ from SAMCEF are Number of dof's=484, Total length $=557.1348 \mathrm{~m}$, Total Volume $=378.5264 \mathrm{e} 3 \mathrm{~m} 3$, Total mass $=6.5845 \mathrm{~kg}$.

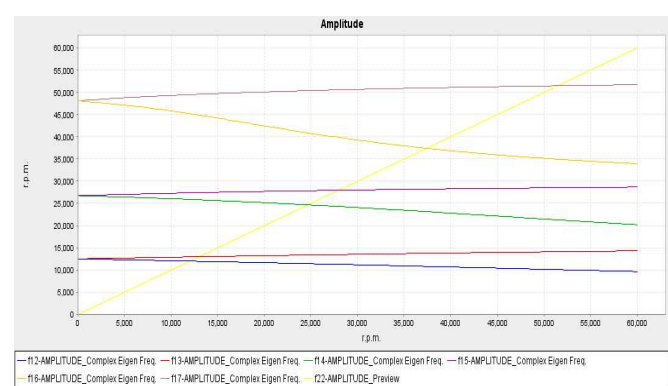

(a) Campbell Diagram

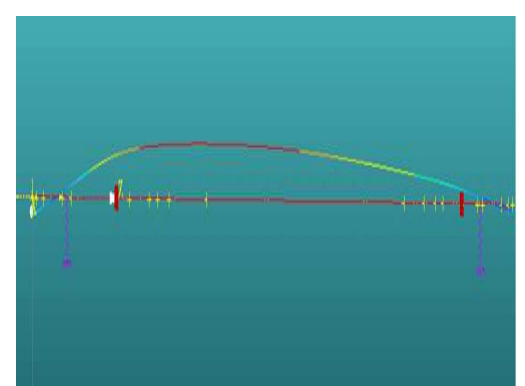

(b) $1^{\text {st }}$ Mode

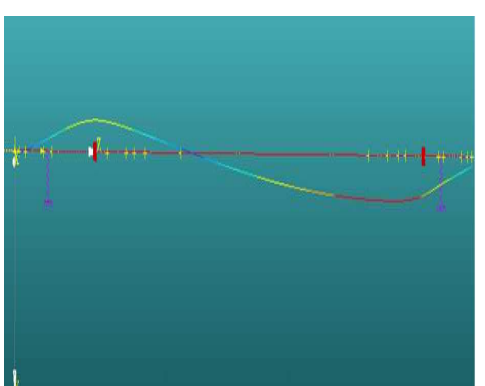

(c) $2^{\text {nd }}$ Mode

Figure 12: Campbell Diagram with Bearing Stiffness ( $\mathrm{K}=30 \mathrm{MN} / \mathrm{m})$ and Mode Shape of Beam Corresponding to 1st mode (Critical speed: 12951RPM), 2nd mode (Critical speed: 27946RPM ).

Figure 12 shows the Campbell diagram and two mode shapes, in both cases, displacement is very small which is nearer to $1 \mathrm{~mm}$. But the solid shaft configuration with bearing stiffness $(\mathrm{K})$ as $30 \mathrm{MN} / \mathrm{m}$ is more reliable than the hallow shaft configuration. So this configuration further considered for Harmonic and Transient analysis.

\subsection{Harmonic Response Analysis}

In SAMCEF, for harmonic analysis, calculated unbalanced mass is added to the system at lumped masses of compressor and turbine disks. The plots of Unbalance peak responses with respect to the displacements and reaction forces at different positions of the rotor system are analysed for the analysis. 

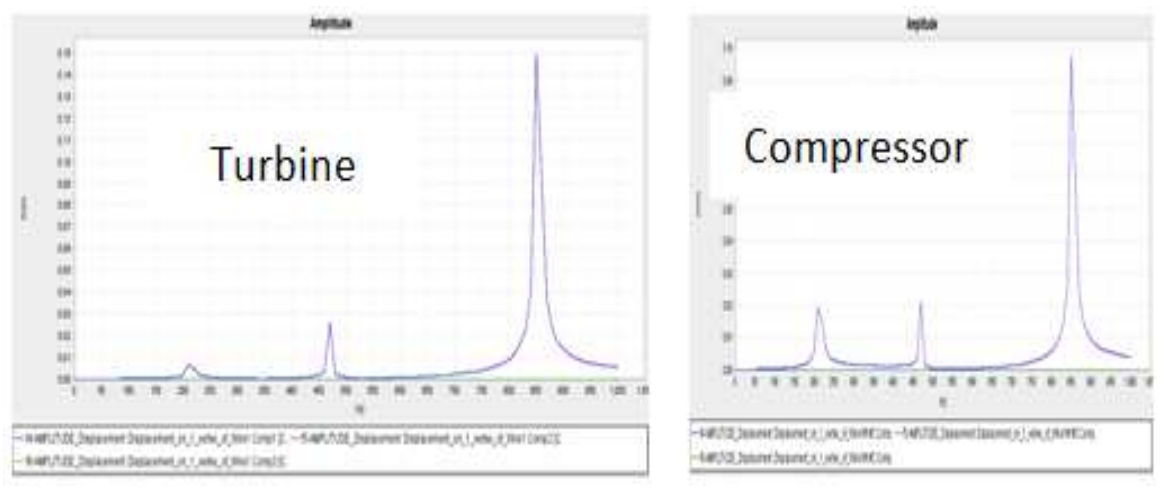

Figure 13: Displacement Amplitude at Turbine and Compressor.
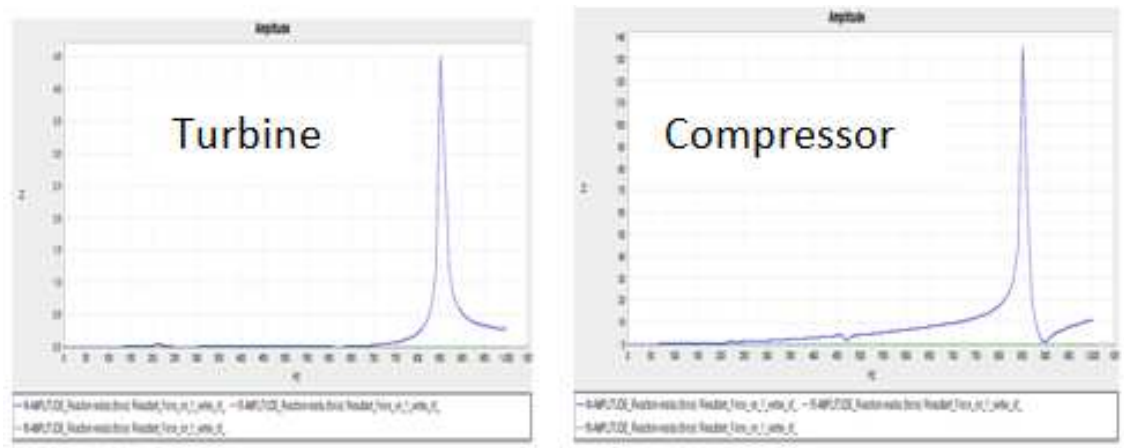

Figure 14: Resultant Force Amplitude at Turbine and Compressor

Figure 13 shows that the displacement amplitude value in shaft is more (15 microns) at outside the operating speed; there is no peak response at our operating speed. Small amplitudes are raised at first and second synchronous forward whirls. At first mode displacement amplitude is 1 micron and at second mode it is 2.5 microns. Figure 13 shows that the displacement amplitude value in compressor is more (10 microns) at outside the operating speed; there is no peak response at our operating speed. Small amplitudes are raised at first and second synchronous forward whirls. At first mode displacement amplitude is 2 microns and at second mode it is 2 microns. Figure 14 shows that the Resultant force amplitude value in shaft is more ( 2 Newton) at outside the operating speed, there is no peak response at our operating speed. Small amplitudes are raised at first and second synchronous forward whirls. At first mode resultant reaction force amplitude is 0.2 Newton and at second mode it is 0.1 Newton. Figure 14 shows that the Resultant force amplitude value in compressor is more (140 Newton) at outside the operating speed, there is no peak response at our operating speed. Small amplitudes are raised at first and second synchronous forward whirls. At first mode Resultant reaction force amplitude is 3 Newton and at second mode it is 5 Newton.
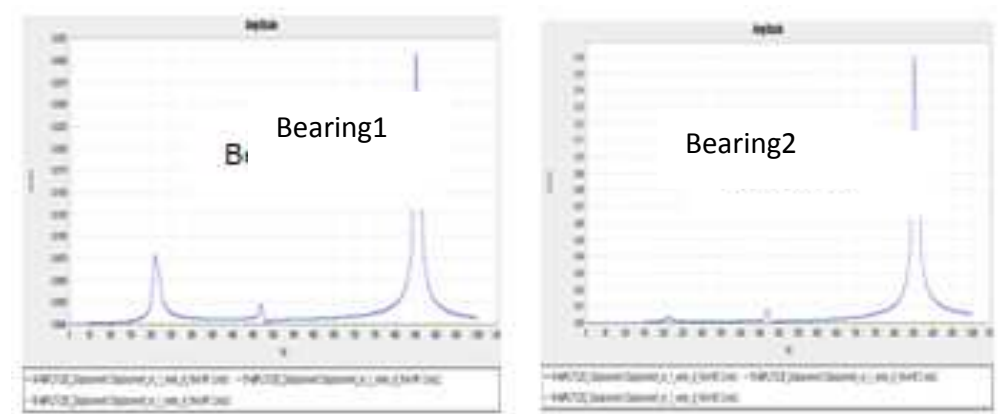

Figure 15: Displacement Amplitude at Bearing1 and 2. 

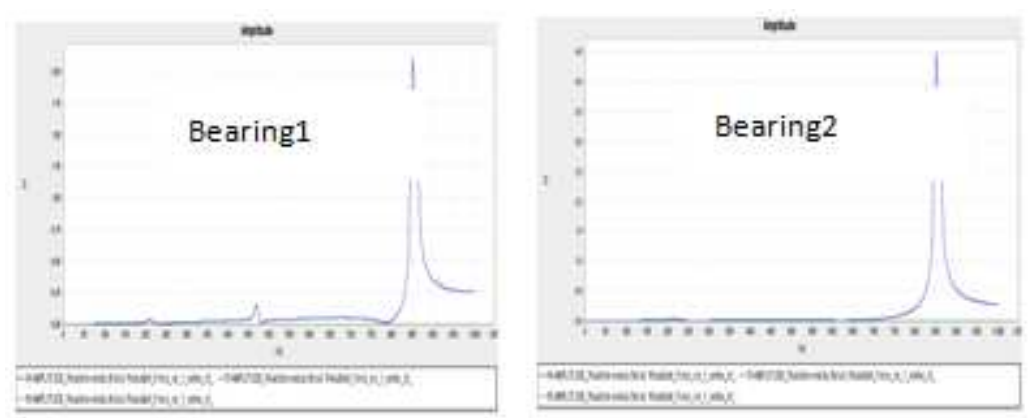

Figure 16: Resultant Force Amplitude at Bearing1 and 2.

Figure15 shows that the displacement amplitude value at bearing1 is more (32.5 microns) at outside the operating speed; there is no peak response at our operating speed. Small amplitudes are raised at first and second synchronous forward whirls. At first mode, displacement amplitude is 8 microns and at second mode it is 2 microns. Figure 15 shows that the displacement amplitude value in bearing 2 is more (160 microns) at outside the operating speed, there is no peak response at our operating speed. Small amplitudes are raised at first and second synchronous forward whirls. At first mode displacement amplitude is 3 microns and at second mode it is 8 microns. Figure 16 shows that the Resultant force amplitude values in bearing1 is more ( 2 Newton) at outside the operating speed, there is no peak response at our operating speed. Small amplitudes are raised at first and second synchronous forward whirls. At first mode displacement amplitude is 0.5 Newton and at second mode it is 0.2 Newton. Figure 15 shows that the Resultant force amplitude value in bearing 2 is more (4.5 Newton) at outside the operating speed; there is no peak response at our operating speed. Small amplitudes are raised at first and second synchronous forward whirls. At first mode displacement amplitude is 0.3 Newton and at second mode it is 0.2 Newton.

\subsection{Transient Analysis f Rotor Dynamic System:}

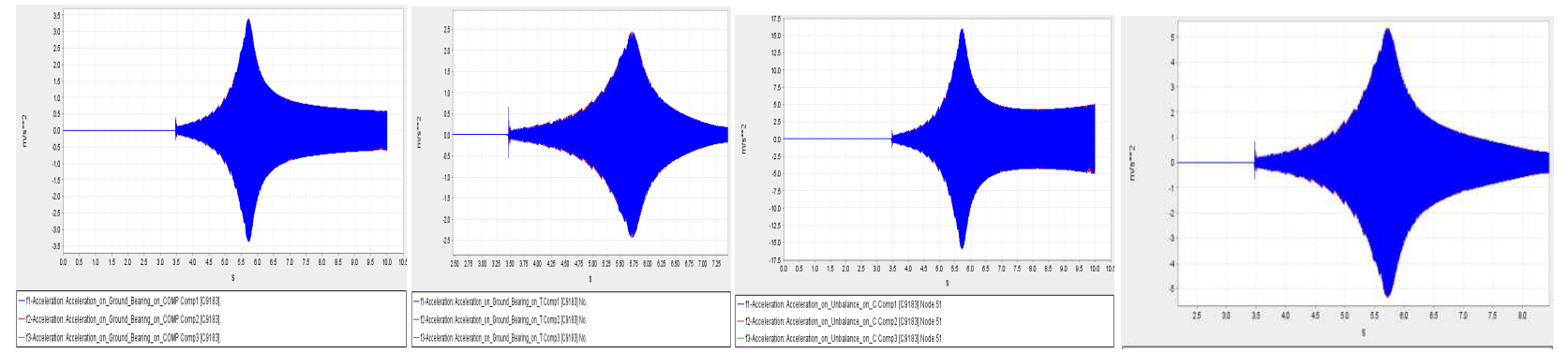

Figure 17: Transient Response of Acceleration at Bearing 1, Bearing2, at Compressor and Turbine Lumped Mass.

From the Figure 17, the change of accelerations of the components with respect to time is started at 3.5 seconds, peak locations observed between 5.5 to 6 seconds are taken into the account. The peak acceleration values of components with respect to their positions at bearing1 is $3.5 \mathrm{~m} / \mathrm{s}^{2}$, Bearing 2 is $2.5 \mathrm{~m} / \mathrm{s}^{2}$, at compressor lumped mass is $16 \mathrm{~m} / \mathrm{s}^{2}$ and at turbine lumped mass is $6 \mathrm{~m} / \mathrm{s}^{2}$

\section{CONCLUSIONS}

An analysis was carried out for predicting the Dynamic stability characteristics of the rotor dynamic system having the rotor shaft with supporting bearing elements. From the numerical analysis of rotor dynamic system in SAMCEF, Solid stepped shaft with simply supported (bearing at ends) configuration having the bearing span of $479.3 \mathrm{~mm}$ is finalised. This has produced better results at bearing stiffness $30 \mathrm{MN} / \mathrm{m}$ in Critical speeds and Stability analysis. Unbalance calculations 
of the finalised configuration were calculated according to the API Standards for the Harmonic response analysis. And the peak responses of the displacements and Resultant reaction forces are observed. Time Transient response analysis of the final rotor dynamic configuration carried out for the analysis of the Acceleration and displacement of the rotor components with respect to time variations. The critical speed margin of the Rotor shaft configuration can be improved by Squeeze Film Dampers in the bearing plane. It will increase the complexity of the system but also increases the reliability. Based on the above design and analysis of the rotor dynamic system configuration will be finalised. Once the individual component design in finalised the rotor dynamic analysis results will be refined by taking the actual size and shape of the turbine and compressor for different stiffness and damping values including squeeze film dampers if exists. The unbalance response and transient response of the final configuration also will be evaluated to understand the vibration pattern in operating range.

\section{REFERENCES}

1. Rankine W. J., (1869).On the Centrifugal Force of Rotating Shafts, Engineer periodical, Vol. 27, pp. 249

2. Jeffcott H. H., (1919). The Lateral Vibration of Loaded Shafts in the Neighbourhood of a Whirling Speed: The Effect of Want of Balance, Philosophical Magazine, Series 6, Vol 37. P. 304.

3. Stodola A., (1945). Steam and gas turbines :New York: P. Smith

4. Biezeno, C.B. and Grammel, R.,(1939). Technische Dynamik : Springer Verlag

5. Lund J. W., (1965). Rotor Bearing Dynamic Design Technology, Part III: Design Handbook for Fluid Film Bearings. Mechanical Technology Inc., Latham, New York, AFAPL-Tr-65-45

6. Gunter, E. J., Jr.,(1966). Dynamic stability of rotor-bearing systems, NASA SP-113, 29.

7. Bhat, R.B., Rao, J.S. and Sankar, T.S.(1982). Optimum Journal Bearing Parameters for Minimum Unbalance Response in Synchronous Whirl, Journal of Mechanical Design, ASME, 104, p. 339.

8. Rao J.S.,(1982). Conditions for Backward Synchronous Whirl of a Flexible Rotor in Hydrodynamic Bearings, Mechanism and Machine Theory, Vol. 17, No. 2, 143-152.

9. Genta G., (1992). A Fast Modal Technique For The Computation Of The Campbell Diagram Of Multi-Degree-Of-Freedom Rotors, Journal of Sound and Vibration, Vol. 155, issue 3, pp. 385-402.

10. Sinou J.J., Villa C., Thouverez F.,(2005). Experimental and Numerical Investigations of a Flexible Rotor on Flexible Bearing Supports, International Journal of Rotating Machinery, Vol.3, pp. 179-189.

11. Friswell M.I., Penny J.E.T., Garvey S.D.,(2000). Model Reduction for Structures with Damping and Gyroscopic Effects, International Conference on Noise and Vibration Engineering (ISMA 25), September 13th-15 ${ }^{\text {th }}$.

12. Al-Bedoor B.O.,(2001). Modelling the coupled torsional and lateral vibrations of unbalanced rotors, Computer Methods in Applied Mechanics and Engineering, Vol. 190, pp. 5999-6008.

13. Carnegie, A., and Eckert, W.F , (1992). A Reduction Procedure for Finite Element Models of Beams and Shafts, Journal of Sound and Vibration, Vol. 1 56, pp. 559-570.

14. Rayleigh, J.W.S., (1877).Theory of Sound: MacMillan, London.

15. Nelson, HD., and Mc Vaugh, JM., (1976). The Dynamics of Rotor-Bearing Systems Using Finite Elements, ASME Journal of Engineering for Industry, Vol. 98, pp. 593600. 
16. Sinou J.J., Villa C., Thouverez F, (2008) Stability and vibration analysis of a complex flexible rotor bearing system, Communications in Nonlinear Science and Numerical Simulation vol. 13 (4), pp. 804-821.

17. Lees A.W., Sinha J.K., Friswell M.I., (2009). Model-based identification of rotating machines, Mechanical Systems and Signal Processing ,23, pp. 1884-1893.

18. Khulief Y.A., Mohiuddin M.A.,(1997). On the dynamic analysis of rotors using modal reduction, Finite Elements in Analysis and Design 26, pp. 41-55.

19. Sinha J.K., Lees A.W., Friswell M.I.,(2004). Estimating unbalance and misalignment of a flexible rotating machine from a single run-down, Journal of Sound and Vibration 272, pp. 967-989

20. Morais T.S., Der Hagopian J., Steffen V. Mahfoud Jr, J.,(2014). Optimization of unbalance distribution in rotating machinery with localized non linearity, Mechanism and Machine Theory, 72, pp. 60-70.

21. Chun-biao Gan, Yue-hua Wang, Shi-xiYang, Yanlong Cao, (2014). Nonparametric modeling and vibration analysis of uncertain Jeffcott rotor with disc offset, International Journal of Mechanical Sciences, 78, pp. 126-134.

22. Qinkai Han, Fulei Chu,(2015). Parametric instability of flexible rotor-bearing system under time-periodic base angular motions, Applied Mathematical Modelling, pp. 4511-4522.

23. L. Umamaheswararao \& K. Mallikarjunarao, "Design and Analysis of Turbine Blade by Using Fem”, International Journal of Mechanical Engineering (IJME), Vol. 4, Issue 1, pp. 1-8

24. Abdul Kadir Muhammad, Shingo Okamoto \& Jae Hoon Lee, "Comparison between the One Piezoelectric Actuator and the Two Ones on Vibration Control of a Flexible Two-Link Manipulator Using Finite Element Method", International Journal of Mechanical Engineering (IJME), Vol. 5, Issue 1, pp. 25-42

25. Wactaw Kollek \& Urszula Radziwanowska, "The Modernization of Gear Micropump Casing with the Use of Finite Element Method", IMPACT: International Journal of Research in Engineering \& Technology (IMPACT: IJRET), Vol. 2, Issue 7, pp. 69-76,

26. Ahmed M. Emarah, Kamal G. Metwally \& Abdelhamid I. Zaghw, "Comparative Analytical Study of Reinforced Concrete Wall Subjected to Blast Loading Pattern”, BEST: International Journal of Management Information Technology and Engineering (BEST: IJMITE), Vol. 5, Issue 09, pp. 73-78 